\title{
Tiempo y espacio en geografía: dilemas y reflexiones ${ }^{1}$
}

\author{
María Laura Silveira ${ }^{2}$
}

\begin{abstract}
RESUMEN
La pregunta fundamental que formulamos es cómo empirizar el tiempo, en su indisolubilidad con el espacio, para entenderlos como una condición unitaria de existencia. Para ello, en primer lugar, retomamos algunas nociones de tiempo en filosofía, con especial atención a la búsqueda de categorías universales; en segundo lugar discutimos algunas propuestas en geografía que tratan tiempo y espacio como conceptos puros y otras que integran ambas categorías; en tercer lugar, abordamos las categorías evento y forma como modo de acercarnos a una dialéctica concreta; en cuarto lugar discutimos la empirización del tiempo a partir del fenómeno técnico y de la periodización y, finalmente, analizamos la posibilidad de una geografía de la existencia en el período de la globalización.
\end{abstract}

Palabras clave: Relación espacio-tiempo, empirización, técnica, período, categorías.

\begin{abstract}
The fundamental question is how empirizate time, in its indissolubility with space, to understand them like a unitary condition of existence. For this, in the first place, we present some notions of time in philosophy, with special attention to universal categories. Second we argue some proposals in geography that treat time and space like "pure" concepts and others authors that integrate both categories. In third place, we used the categories "event" and "form" like way to approach us to a concrete dialectics. Fourth we argue the empirization of time from the technical phenomenon and periodization. Finally, we analyze the possibility of geography of the existence in the period of the globalization.
\end{abstract}

Key words: Space-time relation, empirization, tecnhique, period, categories.

1 Artículo recibido el 20 de enero de 2013, aceptado el 3 de febrero de 2013 y corregido el 10 de marzo de 2013.
2 Consejo Nacional de Investigaciones Científicas y Técnicas (CONICET), Instituto de Geografía, Universidad de Buenos Aires (Argentina).

E-mail: laurasil@usp.br 
Comprender el tiempo y sus relaciones con el espacio ha sido una preocupación permanente y recurrente a lo largo de la historia, tanto en la filosofía como en las disciplinas particulares. En el pensamiento geográfico el apelo ora a un espacio geométrico congelado en el tiempo, ora a un espacio meramente material, soporte para un tiempo cronológico, se han revelado como tonos extremos de una melodía que refleja la persistencia en considerar el tiempo en su forma más abstracta. De allí que una pregunta fundamental es cómo empirizar el tiempo, en su indisolubilidad con el espacio, para entenderlos como una condición unitaria de existencia.

Para ello proponemos una discusión en cinco partes: en la primera buscamos una breve síntesis de algunas nociones de tiempo, con especial atención a la búsqueda de categorías universales; en la segunda abordamos algunos de los esfuerzos más importantes realizados en geografía para discutir las relaciones entre espacio y tiempo; en la tercera incorporamos las categorías evento y forma como modo de acercarnos a una dialéctica concreta; en la cuarta discutimos la empirización del tiempo a partir del fenómeno técnico y de la periodización y, en el apartado final, analizamos la posibilidad de una geografía de la existencia en el período de la globalización.

\section{Nociones de tiempo y búsqueda de categorías universales}

En la extensa historia de las ideas que separa a los antiguos griegos de la teoría de la relatividad sucesivas, incompletas y opuestas nociones de tiempo atravesaron las épocas, combinándose con otras tantas definiciones de espacio, en indagaciones sobre el mundo y las condiciones de su existencia. En diapasones diferentes, diversos pensadores parecían compartir una preocupación fundamental, como era la de encontrar categorías universales para aprehender, explicar y medir el tiempo. De allí la presencia de ideas como movimiento, permanencia, ritmo, medida, duración y dimensión entre otras, que permeaban un debate más profundo: ¿el tiempo es una categoría de nuestro pensamiento o es una realidad material?
En su célebre poema "Sobre la naturaleza", Parménides expresaba su sentencia más conocida: el Ser es y el No Ser no es. Negaba, de ese modo, la realidad del movimiento y del tiempo porque ambos le figuraban opuestos a la razón lógica (Parménides, 1983). Como señala Hottois (1999), su fidelidad al principio de identidad y de no contradicción le impedía pensar que el devenir existiese lógicamente, pues la mezcla del ser y el no ser era vista como contradictoria e inconcebible. Lejos de tal fidelidad, Platón irá más allá al aseverar que es imposible pensar una idea si no se comprende el conjunto relacional en el cual esta se inscribe. La idea de reposo es inconcebible sin la idea de movimiento, así como la del ser sin la del no ser. Aunque fundada en el idealismo, esta aproximación dialéctica permitía entonces comenzar a pensar el movimiento. En la compleja obra de Aristóteles, una sinonimia parecía vislumbrarse. Para ese filósofo no existe tiempo donde no hay movimiento $y$, por consiguiente, el tiempo es una medida o un número para el movimiento. Esta idea será recusada, de algún modo, por Plotino, en el siglo III de la era cristiana, para quien no es necesario mensurar el tiempo para que exista, pues todo tiene una duración aunque esta no sea medida (Piettre, 1997).

En el siglo IV San Agustín retoma con fuerza la idea de que el tiempo es desprovisto de realidad material y externa, pues existe solo en nuestro espíritu. En su elucubración, si el pasado ya pasó y el futuro no llegó, solo existe el presente que no puede permanecer como tal más que un instante. Aquí, menos que a la espesura del presente, a lo que se le atribuye estatus ontológico es a la eternidad. En el mundo antiguo, tanto la tradición idealista como la materialista tuvieron un fuerte trazo en común que era una cierta idea de eternidad que englobaba al presente, pero también al pasado y al futuro. El tiempo de los hombres parecía aun confundirse con el tiempo cósmico para unos y con el tiempo divino para otros.

En los siglos XII y XIII retornan las ideas aristotélicas y desplazan a las formas de idealismo platónicas y agustinianas. La visión del tiempo como eternidad parece ceder su lugar a la aceptación de un cierto movimiento. Para Santo Tomás de Aquino una cosa está 
en movimiento si fue impulsada por un móvil anterior pero, en definitiva, todo remite a un primer motor que se mueve por sí y es el origen trascendente de la cadena de acontecimientos (Hottois, 1999). El geocentrismo completará esa cosmovisión medieval que encontrará sus límites en la revolución copernicana.

Más tarde, la modernidad clásica hallará en las formulaciones de Descartes importantes fundamentos. Nueva forma de pensamiento, la razón analítica conduce a escindir una cosa en sus elementos, mientras que la geometría analítica hace corresponder los números y las formas espaciales y se generaliza la mecánica como ciencia matemática del movimiento, tal como desarrollada por Galileo. Dimensión del tiempo, el movimiento no solo es considerado sino también medido, sustituyendo la idea de un tiempo eterno por una visión matematizada del tiempo y una visión geométrica del espacio.

Verdadero cambio de paradigma en el pasaje del siglo XVII al siglo XVIII, el modelo de la física de Newton fue cuestionado más tarde. La perspectiva mecanicista del universo se fundamentaba, entre otros elementos, en la existencia de un tiempo absoluto, material, expresado matemáticamente, que puede ser visto como sinónimo de duración, aunque sin negar un tiempo percibido a través del movimiento y pasible de ser dividido convencionalmente. Se concebía un espacio absoluto concomitante a un tiempo absoluto, mientras que espacio relativo y tiempo relativo eran solo medidas externas, hijas de la sensibilidad.

Kant ha marcado el debate sobre el tiempo y el espacio y sus ideas han sido retomadas, explícita o implícitamente, por un importante número de geógrafos. Escritas en el final del siglo XVIII, sus obras aún hoy continúan a influenciar diversas matrices de pensamiento. La razón presenta estructuras o formas idénticas para todos que, independientes de la experiencia, están en nuestra facultad de conocer. Esas formas son el tiempo y el espacio, es decir, categorías universales a priori, imprescindibles para conocer la materia, para aprehender los contenidos, contingentes y a posteriori. De ese modo, no son espaciotemporales las cosas sino las formas a priori con las cuales las vemos, transformando noúmenos (cosas) en fenómenos. En palabras de Kant (1984: 120): "el tiempo no es un concepto empírico derivado de experiencia alguna, porque la simultaneidad o la sucesión no serían percibidas si la representación a priori del tiempo no les sirviera de fundamento". El tiempo "es una representación necesaria que sirve de base a todas las intuiciones" (Kant, 1984: 120) y permite entender los conceptos de mudanza y movimiento y la unión de predicados opuestos. Se admite ahora que el ser puede ser y no ser como fundamento del cambio, algo que sería contradictorio o imperceptible si no existiesen tales categorías universales a priori. Sin embargo, es la afirmación de la existencia de tales categorías lo que está en la base de una visión separada del tiempo y el espacio. Son categorías permanentes que parecen atravesar las épocas, orientar la formulación de conceptos empíricos y captar los contenidos de la materia. Sin esas formas del pensamiento, no habría otras más específicas y más próximas a los contenidos materiales. Aquí la relación tiempoespacio no es propiamente histórica sino lógica, porque se trata de dos modos igualmente basilares del pensamiento.

En opinión de Piettre (1997: 39-40) las filosofías antigua y moderna se han esforzado en hacer del tiempo algo menos concreto pero "la filosofía contemporánea, desde Hegel y Nietzsche, ha intentado rehabilitar el tiempo y disminuir, por decirlo de ese modo, el privilegio del Ser sobre el devenir y de la Eternidad sobre el tiempo". Hasta el siglo XVIII y especialmente por la fuerza de la denominada revolución científica, el tiempo no es visto propiamente como devenir. De una reflexión logoteórica propia de la filosofía griega antigua y de los escritos de San Agustín y Santo Tomás, el pensamiento se orientó hacia una cierta matematización del movimiento, propia de una visión mecanicista, donde tiempo y movimiento parecen fundirse y confundirse. Si la antigüedad revela, grosso modo, la eternización del tiempo porque el movimiento resulta contradictorio, la modernidad asocia tiempo y movimiento $y$, de ese modo, se prepara para medirlo. Aceptado el movimiento como tiempo, la modernidad parece conducir a un espacio geométrico, homogéneo, inmutable, eternizado, continente, pasible también de ser medido. Ambos, 
tiempo y espacio son absolutos, están escindidos y su asociación, cuando existe, parecía ser fruto del pensamiento.

Sin embargo, el pensamiento de Leibniz trae una contribución esencial al entender que todo está ligado en el universo. Tanto las etapas de evolución del universo, como las mónadas que son las sustancias simples que lo constituyen, están vinculadas entre sí. Pero, además, explica que "todo ser creado está sujeto al cambio" (Leibniz, 1983: 24) y agrega que "como todo cambio natural se hace por grados, algo cambia y algo queda" (Leibniz, 1983: 25). Por eso hay una multitud en la unidad o en lo simple. Habría una temporalidad inherente al ser que no puede ser dejada de lado. Cassirer (1993: 255) también destacaba que Leibniz no intenta subordinar "lo múltiple a lo uno, lo cambiante a lo permanente, sino que parte del supuesto de que ambos momentos no pueden explicarse más que recíprocamente". Aquí el principio que orienta la explicación es la continuidad, en las antípodas del pensamiento cartesiano, cuya base de entendimiento es separar radicalmente las cosas. En el espacio y en el tiempo, el mundo se mantiene unido. Es relacional y, por eso, racional, porque la razón es la facultad de enlazar (Hottois, 1999) y la oposición de conceptos permite comprender que el pensamiento relacional no admite conceptos puros.

Es fundamentalmente a partir de Hegel que la dimensión histórica es introducida en el pensamiento occidental (Hottois, 1999). Ese filósofo busca conciliar razón y devenir en un pensamiento dialéctico, en el cual la síntesis revela la necesidad de comprender un concepto a partir de su contrario que es, por eso, su complemento. El pensamiento adquiere un movimiento dialéctico y busca ser histórico. Estamos frente a un nuevo método, capaz de incluir el tiempo como base del entendimiento. No se trata del movimiento o la duración, sino del tiempo de la historia de los hombres. Con Marx, el método dialéctico y el tiempo adquieren empiricidad al trabajar las categorías fundamentales del análisis económico como tierra, trabajo, capital, moneda, técnica y otras, en el contexto de cada período histórico.

Considerada una revolución epistemológica, la teoría de la relatividad significa un cambio radical en la concepción del tiempo en las ciencias exactas pero también en la filosofía. Se abandona el tiempo absoluto e idéntico para todos, de raíz newtoniana, para llegar a la idea de un espacio-tiempo cuatridimensional. En esta perspectiva ya no es posible disociar las coordenadas de un cuerpo en el espacio de las coordenadas del mismo cuerpo en el tiempo. Tiempo y espacio no son absolutos, sino relativos. En otras palabras, para Einstein no hay un tiempo cósmico para todo el universo, sino que "cada trozo de materia tiene su propio tiempo local" (Russell, 1983: 282). En esta interpretación, el mundo no es visto como una multiplicidad de partículas en movimiento, sino como una multiplicidad cuatridimensional de acontecimientos. Eso significa que ya no hay distancia entre puntos sino intervalos entre acontecimientos, lo cual nos permite pensar la idea de espacio-tiempo. En la opinión de Santos (1986: 206), la idea de espacio cuatridimensional es promisora porque "refuerza la noción de espacio relativo, es decir, del espacio considerado como un sistema de relaciones o como un campo de fuerzas; así el tiempo se impone como una dimensión esencial".

La duración ha sido otra cuestión recurrente en los debates sobre el tiempo. Aquí es interesante mencionar que Bergson (1923: 88-89) se preguntaba: "¿qué restará del tiempo si le eliminan la sucesión?" y escribía "la cosa y el estado no son sino instantáneas artificialmente tomadas en la transición" (Bergson, 1923:54), que es la duración y tiene una viscosidad. En la interpretación de Piettre (1997: 46), Bergson señala la importancia de diferenciar un tiempo abstracto, que corresponde al tiempo del reloj, al tiempo medido en física, del tiempo concreto, es decir, la duración, la duración experimentada, vivida por la conciencia. Es Bachelard uno de los mayores críticos a esa idea cuando asevera que "con la Relatividad apareció el pluralismo temporal. Para la Relatividad, existen varios tiempos que, sin duda, se corresponden y que conservan órdenes de desarrollo objetivos pero que no mantienen duraciones absolutas. La duración es relativa" (Bachelard, 1950: 90). Y agrega que es más apropiado referirse a la riqueza y densidad del tiempo que a su duración, pues el tiempo "no aparece continuo sino bajo una cierta espesura, gracias a la superposición de varios tiempos indepen- 
dientes" (Bachelard, 1950: 92). Oponiéndose a Bergson cuando se refiere a la viscosidad de la duración que hace del pasado una sustancia del presente, Bachelard (1950) afirma que, en tal interpretación, el valor creativo del devenir está limitado por la idea de continuidad fundamental.

Fernand Braudel (1989) coincide al señalar la duración como algo relativo ya que el tiempo del mundo es imperioso por irreversible y por transcurrir al ritmo que gira la tierra, pero las duraciones que distinguimos son solidarias unas de otras y, particularmente, las fragmentaciones de las duraciones que son creaciones de nuestro espíritu. Entendiendo el tiempo de la historia como una realidad concreta y viva, Marc Bloch (1975: 37) ya había explicado que de la antítesis de lo continuo y del cambio perpetuo provenían los grandes problemas de la investigación histórica.

Más recientemente, Bruno Latour (1991) propone diferenciar, de un lado, el tiempo del calendario y, de otro, la historicidad, pues: "el tiempo del calendario sitúa bien los eventos en relación a una serie regulada de fechas pero la historicidad sitúa los mismos eventos en relación a la intensidad" (Latour, 1991: 92). A partir de lo que denomina constitución moderna, el autor considera que nos formamos la idea de un tiempo que pasa que no es otra cosa que una forma particular de historicidad (Latour, 1991). En divergencia con el tiempo kantiano, Latour (1991: 101) escribe: "el tiempo no es un cuadro general sino el resultado provisorio del vínculo de los seres".

Con todo, el aporte de la fenomenología y el existencialismo al debate sobre el tiempo fue, sin duda, decisivo. El tiempo se vuelve condición para el entendimiento del objeto. Siguiendo a Husserl (1990: 98), el objeto "no es ningún pedazo ingrediente del fenómeno, en su temporalidad tiene algo que no se deja encontrar en el fenómeno y en él disolverse y que, sin embargo, se constituye en el fenómeno. Se expone en él y está en él evidentemente dado como "siendo»". Y, frente a un fenómeno presente, es la retención la que nos permite percibir un objeto temporal originario y solo en tal conciencia el tiempo puede ser dado. Analizando la obra de Husserl, Borzaga (1966: 126) plantea que el tiempo, para la fenomenología, es una intuición de varios elementos sucesivos. Esa continuidad es un recordar espontáneo, en el cual cada momento, con un significado propio, adquiere su riqueza al relacionarlo con los momentos anteriores. De allí que el saber es un reconocimiento de todos los objetos tal como aparecen en el tiempo.

En el sistema de ideas de Heidegger, espacio y tiempo no son a priori, sino que se esencian a partir de los eventos: "el origen del espacio y del tiempo es el espacio-tiempo y la mediación es el evento" (Heidegger, 2003: 297). Ese espacio-tiempo es después dividido en esas dos dimensiones que, tantas veces, parecen irreconciliables. Por ello el filósofo se pregunta: “¿por qué y bajo qué presupuestos la separación de espacio y tiempo es históricamente necesaria?" (Heidegger, 2003: 299). Espacio y tiempo, a los que se refiere como "formas vacías del orden" (Heidegger, 2003: 299), son objeto de una indagación más incisiva: "la pregunta es sin embargo por el derecho y la procedencia de estas formas vacías, cuya verdad no ha sido aún probada en razón de su corrección y utilidad en el campo del cálculo" (Heidegger, 2003: 299). Y más tarde reflexiona: "¿se puede intentar partir de la pregunta de la 'unidad' de 'espacio y tiempo' según la representación usual?” (Heidegger, 2003: 299) y responde que la unidad del espacio y del tiempo es la del origen (Heidegger, 2003: 302). El espacio-tiempo contiene una riqueza mayor que la expresada a través de la matematización del espacio y del tiempo (Heidegger, 2003). El filósofo (Heidegger, 2012: 75) planteaba que el tiempo se ha usado ingenuamente como criterio óntico para distinguir un ente "temporal", que son los procesos de la naturaleza y los acontecimientos de la historia, y un ente "intemporal", que son las relaciones espaciales y numéricas. Para Heidegger, lo que separa la cosa de su manifestación es el tiempo, un proceso.

En la reflexión de Berger (1964: 133) el espacio es una serie reversible y el tiempo, una serie irreversible porque "son los eventos que introducen la irreversibilidad". El tiempo "no tiene dimensión, nada lo limita, nada lo circunscribe", no encierra nada, no tiene interior $y$, al contrario, el espacio puede ser definido como una forma, que puede insertar 
y contener en ella otras estructuras, mientras que a su alrededor puede haber otras formas. Por esas razones, concluye el autor, el espacio tiene una función esencialmente realizante, permite plantear la existencia de contenidos no actuales; el espacio es "posibilidad de afirmación existencial" (Berger, 1964: 133), en cuanto el tiempo tiene una función de reducir a la nada, no realizante $y$, frecuentemente, es confundido con sus contenidos.

En este contexto parece importante volver a Simmel (2006) cuando, analizando la filosofía hegeliana, asevera: "el ser puede solo radicalmente disolverse en el devenir cuando se deja a cada ser, determinado como tal, ligado a su opuesto, que puede ser solucionado por medio de un proceso o un acontecer" (Simmel, 2006: 103). Lejos de agotar un debate tan complejo, buscamos sintetizar aquí algunos elementos que permitan comprender ciertos fundamentos de una disciplina histórica como la geografía.

\section{Tiempo y espacio en geografía: esfuerzos y dilemas de los conceptos puros}

Menos persistentes habrían sido los dilemas si hubiésemos Ilevado en cuenta el consejo de Bagú (1986: 106) para quien el espacio es "un fragmento de la realidad social hecho de la misma materia que el tiempo" y "un modo de organizarse el tiempo". En efecto, las relaciones espacio-tiempo han sido una cuestión recurrente en geografía, a veces con influencias más o menos marcadas de los debates filosóficos, como en la clara impronta del pensamiento kantiano, otras veces revelando cierta impermeabilidad frente a las nuevas ideas o a su profundidad, como en los diversos existencialismos. La persistencia de debates de índole clasificatoria, como la rotulación apresurada de ciertas ideas geográficas usando el nombre de grandes corrientes como estructuralismo o funcionalismo entre tantas otras, o la infértil oposición geografíahistoria parecen haber tomado el lugar de un necesario ejercicio de internalización de categorías externas. Las consecuencias han sido diversas pero podríamos mencionar aquí, de un lado, la fidelidad a una perspectiva empirista que, por entender que las cosas en sí son más concretas que las relaciones que contie- nen, acabó recortándolas de su dinámica y, por eso, se tornó un enfoque abstracto $y$, de otro lado, la intención de construir un conocimiento apto para elaborar generalizaciones sobre la base de una visión geométrica del espacio y de un lenguaje matemático, una forma de idealismo que despreció el tiempo histórico.

En el primer grupo podríamos incluir las interpretaciones centradas en la relación hombre-medio, que encuentran en la geografía de Vidal de la Blache y sus discípulos los trabajos más destacados. En la segunda década del siglo XX Vidal de la Blache (1946) se refería al "medio físico" en su capacidad de influenciar la vida humana, aunque reconocía al hombre como un factor geográfico pues tenía la habilidad de modificar su entorno. Este matiz, considerado por su discípulo Lucien Febvre (1970) una buena razón para diferenciarlo del pensamiento ratzeliano $y$ designar ese debate como posibilismo-determinismo, nos interesa menos que la idea de que el medio físico entraba como una cosa en sí en el esquema explicativo. Es justo reconocer que ese medio físico era visto como pasible de ser transformado por el hombre, como lo expresa claramente Demangeon (1952) al afirmar que las relaciones de los grupos humanos se establecen con el medio geográfico y no ya con el medio físico. Sin embargo y a pesar de definir a la disciplina como el estudio de las relaciones entre el hombre y el medio, el método suponía una verdadera disección, al analizar cada variable en particular, como sugerido por Descartes, y al mutilar la complejidad de las múltiples variables y relaciones.

Presentados como datos, se suceden el clima, el relieve, la vegetación, la población, con el propósito de alcanzar, al final, una síntesis en virtud de la superposición cartográfica. El espacio parece confundirse con la distribución y el tiempo con la evolución de cada variable. No es siempre que vemos la evolución conjunta de las variables en el análisis y, por esas razones, podríamos decir que estamos frente a un esfuerzo que, a pesar de ser empírico, se torna abstracto. El medio físico gana el estatus de una entidad independiente, más o menos atemporal, que es estudiada en sus particularidades y que ayuda a entender otra realidad, como la región. 
Tal vez el estatus epistemológico concedido al medio físico haya sido la mayor divergencia entre la geografía humana francesa y la denominada morfología social de Durkheim y Mauss. Esta corriente sociológica, que proponía la consideración de los hechos sociales como cosas, incluía en el sustrato social no solo los objetos materiales, sino también los productos de la actividad social anterior, el derecho constituido, los usos establecidos, los monumentos literarios y artísticos (Durkheim, 1985). Más allá de las influencias positivistas que podemos reconocer, esas "cosas" que rodeaban a los grupos sociales estaban cargadas de cierta historicidad, eran resultado de un proceso y no algo en sí como parecía ser el "medio físico" de los geógrafos. No obstante, en un momento de la historia de las ideas en el cual la preocupación por definir un objeto, marcar los límites de cada disciplina y explicitar un método eran fundamentales, esa geografía regional reforzó la idea de medio físico en la consabida relación con los grupos humanos. No sería desacertado citar a Ratzel en medio a estas reflexiones, pues sus escritos parecían combinar al mismo tiempo la idea de un territorio inmutable con la de evolución social y política y espacios cada vez más extensos. Ya en 1899 ese geógrafo había señalado que la filosofía de la historia "encontraba en el territorio, que siempre es idéntico a sí mismo, un fundamento inmutable de los acontecimientos cambiantes de la historia" (Ratzel, 1988: 202). El territorio permitía "un punto de referencia fijo" en medio a los cambios vitales.

Algo semejante podría decirse sobre los límites, pues también eran considerados como dados, algo inmóvil y un punto de partida para el estudio de las porciones de la tierra. Cuando Vidal de la Blache, preocupado en encontrar un criterio de regionalización, abandona la cuenca fluvial ya que su dinamismo no le garantiza límites fijos y adopta la región mineralógica por ser una realidad más estática, parece quedar claro que ha conseguido identificar una cosa en sí, capaz de resistir al movimiento histórico. La paradoja tal vez sea que, negándose la temporalidad de las cosas, se adopta una noción de tiempo, pues a partir de una realidad estática seleccionada podremos explicar cómo se transforma una región natural en una región histórica. Esto es también lo que lleva a pensar que la región es una cosa en sí y no un fenómeno. Los vínculos de una región con las demás y las respectivas transformaciones no tendrían como corolario una modificación de los límites. Se transforma la región pero no sus límites. De allí que esto pueda ser visto como una abstracción. Algo que aparece como empírico pero se torna abstracto. Límites y extensión son modos de manifestación de un espacio a priori, así como tal vez el género de vida lo sea de un tiempo también kantiano. Tiempo y espacio están presentes como categorías de pensamiento más que como procesos históricos.

No afirmamos aquí que esas perspectivas no considerasen la historia como una instancia explicativa irrecusable, sino que buscamos señalar la dificultad que revelan por no empirizar el tiempo, es decir, dejar de ver la cosa en sí para aprehenderla en su proceso de tornarse otra cosa. Fue el propio Lucien Febvre (1970: 394) quien pudo escribir: “iqué relaciones han establecido las sociedades humanas de antaño, en las diversas épocas, en las diversas comarcas del globo, con el medio geográfico de su tiempo, tal como podemos intentar reconstituirlo? Es el mismo problema de siempre, exactamente, pero transpuesto del presente al pasado". Buscando establecer puentes con la historia y diferenciarse de la sociología, más específicamente de la morfología social, Febvre (1970), planteaba que el geógrafo debía partir, en todos los casos, del estado de cosas presente pero no estudiarlo tal como nos es dado, bajo pretexto de que sus componentes se explican unos con los otros. Para superar lo que consideraba un error de método en geografía, proponía el análisis de los fenómenos complejos, descomponiéndolos en sus diferentes elementos y estudiándolos uno a uno, separándolos de los otros y con un método comparativo.

En una lectura de su propio tiempo, Camille Vallaux (1929) reconocía dos tendencias dentro de la geografía. La primera, que identificaba como un monismo geográfico, entendía que cabía a la disciplina estudiar la interdependencia entre los tres estados de la materia: litósfera, hidrósfera y atmósfera. Aquí proponía considerar un cuarto estado de la materia para referirse a la transformación de esa unidad de estados de la materia por la 
acción humana, revelando su preocupación con el papel de los grupos humanos y con el tiempo. Concomitante a esa visión que parecía estudiar una masa estática, existía una segunda tendencia que buscaba considerar a la tierra como un organismo, un gran cuerpo viviente. Con la influencia del finalismo, esa idea "transformó la antigua idea de milieu, el complejo de condiciones naturales donde se desarrollan las sociedades humanas" (Vallaux, 1929: 48), pero el autor aconseja conservarla solo en su carácter poético y metafórico y no utilizarla en el futuro. Aquí el tiempo parece ser captado únicamente a partir de una analogía con la biología. En este contexto y buscando una forma eficaz de introducir el tiempo en la definición de espacio, Vallaux (1929: 322) propone la idea de tiempo geográfico: "a ese espacio geográfico determinado se junta una fracción de tiempo donde los fenómenos que contiene evolucionan $[\ldots]$ de manera a soldar indisolublemente las nociones de tiempo y de espacio: pero el tiempo geográfico está estrechamente determinado y cualificado, como el espacio mismo". Y lamentaba que de las matemáticas a la psicología las disciplinas consideren únicamente como espacio científico al espacio geométrico de tres dimensiones, propio de la geometría euclidiana. Sin atributos, tal espacio parece existir fuera de este mundo (Vallaux, 1929).

Sin embargo, un autor como Max Sorre, heredero de la tradición vidalina, realizó un importante esfuerzo de incorporación de la idea de tiempo en geografía y tampoco ignoró los aportes de la teoría de la relatividad, como puede ser percibido en su perspectiva claramente relacional. Escribe el autor (Sorre, 1948: 598): "Como la velocidad de los desplazamientos aumenta, la distancia cesa de ser un obstáculo a las relaciones. Al mismo tiempo que participa materialmente y espiritualmente de una vida más larga, el hombre se hace otra idea del espacio y del tiempo [...] El globo se empequeñece. El espacio y el tiempo han tomado para las generaciones que vienen una significación diferente de aquellas que tuvieron para sus antepasados. [...] Tal vez no es indiferente subrayar aquí su coincidencia con la revisión crítica de las categorías de tiempo y de espacio y con la introducción de la relatividad en el dominio de la filosofía científica".
Carl Sauer (2000) debe ser mencionado también entre los geógrafos que se preocuparon genuinamente con la noción de tiempo y con su operacionalización. Su propuesta es definir, como objeto de la disciplina, el paisaje cultural, que constituye en sí mismo un contenido histórico. Gracias a la fuerza activa de un grupo cultural, el paisaje cultural se forma a partir del paisaje natural, y ese proceso es lo que debería ser estudiado, aunque sin olvidar que la propia cultura no es incólume al paso del tiempo. Sauer (2000: 97), quien como Schlüter, criticaba acerbamente la definición de la geografía como una relación causal, defendía la utilización del método histórico en la investigación geográfica para entender el origen de los fenómenos: "usamos, también, mucho el método histórico. Para comprender cómo una ciudad alcanzó importancia, cómo un cierto tipo de economía vino a caracterizar un paisaje, debe conocerse el origen histórico del fenómeno" y agrega "la geografía, en todas sus ramas, se volvió genética y, por ese motivo, histórica".

No fue poco frecuente la acción de circunscribir el tiempo a un ramo de la disciplina, la geografía histórica, como si esta fuese un desván donde amontonar un conjunto de nociones incompletas y de difícil operacionalización. Esa suerte de atajo epistemológico no libró a la geografía del irrecusable ejercicio de comprender que tiempo y espacio constituyen una condición unitaria de existencia. No obstante, buena parte de la geografía histórica tampoco consiguió enfrentar esa tarea, limitándose a incorporar a la historia la noción de medio físico. Sauer (2000: 80) ya señalaba, refiriéndose a la geografía histórica convencional de inicios del siglo XX, que esta se dedicaba al "estudio de las influencias geográficas en la historia", interpretando eventos históricos como "geográficamente condicionados" (Sauer, 2000: 81). Recientemente, Perla Zusman (2006: 174) Ilama la atención sobre otros aspectos de las concepciones de tiempo y espacio presentes en los trabajos tradicionales de geografía histórica y explica: "la concepción del tiempo como una sucesión entre el pasado y el presente, o entre una serie de etapas, como un cambio de cualidades, y la concepción del espacio como un escenario, región o paisaje, que muda en sus atributos, pero que como unidad significativa aparece históricamente 
inerte, parecerían hablarnos de una particular forma de relacionar ambos términos".

Otro modo de evitar la reflexión fundamental sobre tiempo y espacio fue el de abordar las relaciones entre historia y geografía. Ciertamente más acotado en términos epistemológicos, ese debate atravesó las décadas y aún hoy mantiene vigencia. Brunhes (1988), quien ya se preocupaba con la vaguedad de las relaciones entre la naturaleza y los hombres y afirmaba que existían hechos intermediarios, como los hechos de cultivo o de pesca, que explicaban cómo los hechos naturales actuaban sobre los grupos humanos, escribía al respecto: "es, en efecto, a través del trabajo y de las consecuencias directas de ese trabajo que se establece la verdadera conexión entre la geografía y la historia" (Brunhes, 1947: 274) como si estas últimas fuesen sinónimos de espacio y tiempo. Podemos ver que los elementos que constituyen el medio geográfico, aunque ya no físico, son percibidos como contenidos de las relaciones históricas: "si nos remontamos al pasado, si rehacemos toda la historia a la luz de los hechos geográficos, será necesario mostrar el papel jugado por las rutas, rutas de la seda, rutas de la sal, rutas de las especias, etc., en la evolución de las relaciones históricas entre los grupos humanos" (Brunhes, 1947: 277).

En un texto en el cual discute las relaciones entre la geografía y la historia, Lacoste (1984: 71) expresa: "la articulación metódica de los diferentes niveles de análisis, ya sea que se trate del tiempo o del espacio, es una de las grandes dificultades del razonamiento del historiador o del geógrafo, pero es solamente de ese modo que deviene un saberpensar el tiempo o un saber-pensar el espacio". Quizás aquí el autor pretenda superar la clásica e ingenua división por medio de la cual la historia se preocupa por un ente temporal y la geografía por un ente intemporal, como si fuese posible aprehender el ser sin la perspectiva del tiempo (Heidegger, 2012).

Sin embargo, el enfoque de la relación entre dos cosas en sí, cuya delimitación histórica y territorial sería definida en cada estudio, parece haberse impuesto triunfalmente durante largos años. Nos referimos a la insistencia en definir la disciplina más como el estudio de las relaciones entre el medio físico y el hombre y menos como el estudio del medio geográfico, resultado de una historia permanente y contradictoria de las cosas y de las acciones, en la cual ningún elemento está dado como definitivo ni puede pretender autonomía de significado. Las dualidades se fortalecen y el tiempo parece ser una variable subordinada aun cuando se hable de historia, pues en general se trata de una cronología, de un tiempo abstracto. Estudioso de los paisajes, Gourou (1973: 362) refuerza esa idea al escribir: "la aceleración del cambio de los paisajes humanos, característica de nuestra época, y puro hecho de civilización, plantea con agudeza el problema de las relaciones entre los hombres y el medio físico". Y esa relación era inclusive postulada como objeto de la disciplina en el seno de la denominada geografía aplicada cuando Stamp (1965: 5) subrayaba que solo la geografía podía interpretar esa "íntima relación entre el hombre y su medio" porque "no hay otra materia que como ella trate de entender o interpretar esta relación en su conjunto, tanto en el espacio como en el tiempo".

En el segundo grupo mencionado encontramos algunos esfuerzos de generalización que hicieron del tiempo una variable subordinada. En 1905, el mismo año en que Einstein comenzaba a publicar su teoría de la relatividad, Hettner (1988: 317) escribía: "la realidad es un espacio tridimensional que observamos desde tres puntos de vista. En primer lugar, vemos las conexiones de una interrelación material, desde el segundo punto de vista vemos el desarrollo en el tiempo y desde el tercero la distribución y el orden en el espacio". Si renunciamos a la tercera perspectiva, que debe ser estudiada por las ciencias corológicas y la geografía es una de ellas, la realidad es bidimensional. En esa división del saber, el geógrafo alemán dejaba muy clara una regla metodológica: "para ella [la geografía] el tiempo se sitúa en el fondo de la escena, ya que no estudia el paso del tiempo como tal [...] solo tiene en cuenta el desarrollo histórico con el fin de explicar las condiciones del momento elegido" (Hettner, 1988: 321). No negaba, con todo, la existencia de una geografía histórica. En esta línea, Hartshorne (1978) agregará un elemento a esta compartimentación del saber: los historiadores estudian secciones temporales y los geógrafos, secciones espaciales. La cuestión 
central es que si trabajamos con un espacio divorciado del tiempo acabamos utilizando un modelo, pues no existe un espacio que no sea histórico. En estos autores vemos que la división clara de los objetos de estudio entre las disciplinas se espeja en una vertiente kantiana y corresponde a las dos categorías basilares a priori del pensamiento. Por consiguiente, el tiempo no ha sido negado en estos esquemas analíticos, sino que no participa del conjunto de variables a analizar. Es una delimitación inicial del estudio y una condición estática, pues como explica Hartshorne (1978: 88) "el tiempo está lógicamente implícito" en una investigación, ya que el presente supone cierta extensión del tiempo, una "franja de tiempo suficientemente larga". El tiempo existe como flecha donde elegimos un segmento para situar la investigación, pero no es considerado en su empiricidad, en sus contenidos, continuidades y rupturas. No existe una preocupación por aprehender la historicidad, sino en elaborar un modelo coherente y aplicable universalmente. Estamos frente a categorías, pero faltan los conceptos.

Para David Harvey (1969) las corrientes deterministas y ambientalistas de las décadas de 1920 y 1930, representadas por Semple, Huntington y Griffith Taylor, provocaron una reacción que condujo al estudio de pequeñas áreas y a la elaboración de síntesis regionales. Esto hizo de la geografía un saber de lo singular y la tesis kantiana sirvió a Hettner para mostrar que esa disciplina era más ideográfica que nomotética. Y aclara que, aunque el espacio puede ser estudiado y se pueden proponer conceptos espaciales independientemente de su contenido empírico, lo más lamentable es no haber reconocido la noción de espacio absoluto en la tesis kantiana. A partir de esta noción, todas las localizaciones son únicas, lo que autoriza a suponer a priori regiones con individualidades geográficas, imposibles de ser generalizadas en una teoría.

La consideración del espacio como categoría a priori garantiza la universalidad del saber producido y la contingencia de los contenidos captados. Tal vez regresando a una perspectiva aristotélica, lo que se introduce en el análisis es menos el tiempo y más el movimiento que surge, en el abanico de variables, como algo a ser medido y modelizado. En su metageografía del proceso, inspirada en una metafísica del proceso, heredera de Demócrito y Heráclito y en la cual encontramos el tiempo de la física pero no el de la historia, Brian Berry (1973: 23) se refiere a que "el universo no debería contemplarse como algo constituido por objetos o cosas, sino como una jerarquía completa de pautas (esto es, procesos) de flujo, más o menos amplias, establecidas dentro de sistemas de escala incluso mayor, en los que las «cosas» son rasgos o características del flujo que se autoconservan o autorrepiten, con una cierta permanencia, a pesar de que materia, energía e información estén fluyendo continuamente a través de ellas". Y, aplicando su teoría, afirma: "en geografía urbana, los barrios de una ciudad conservan sus propias características solamente porque es siempre el mismo tipo de personas el que entra y sale de sus límites espaciales; la autoconservación de estos flujos preserva la geografía social de la ciudad" (Berry, 1973: 23). Esa aparente confusión entre tiempo y movimiento puede llevar a imaginar que no es de un espacio estático que esta geografía está tratando. Es lo que vemos en Burton (1988: 420) cuando defiende el uso de la teoría de grafos porque permite tratar desde redes de energía a formas de organización social y a las nervaduras de las hojas, ya que todos esos geógrafos "tienen en común el interés por el «flujo» entre «puntos» en una red de eslabones ordenados por un patrón particular". En otros casos, no solo se excluye el tiempo histórico sino también la propia noción de relatividad, como en la siguiente excerpta de Dacey (1973: 191) sobre distribuciones espaciales: "la región $\mathrm{R}$ está situada en el espacio euclidiano bidimensional $\mathrm{E}$. Aunque no es necesario, se supone en lo que sigue que $\mathrm{R}$ es una región delimitada y conectada a otras, con un área finita $m(R)^{\prime \prime}$. En estas perspectivas las teorías son formuladas a partir de un lenguaje matemático "ya que la forma matemática asegura la transparencia y la ausencia de contradicción" (Bunge, 1988: 403) y entienden que la "posibilidad de predicción es crucial desde el momento en que es el requerimiento básico de toda teoría" (Bunge, 1988: 407). Ante una visión cartesiana y newtoniana como esta, la geografía pierde su naturaleza histórica y se vuelve incapaz de explicar el presente. Con todo, un autor como Burton (1988) afirmará, en la década de 1960, que si la cuantificación en geografía fue mecanicista, las nuevas técnicas utilizadas son probabilísticas y se comienza a hablar de tendencias probables. 
Teorías como la difusión de innovaciones, los lugares centrales y otros modelos urbanos y rurales han transformado el tiempo en un dato y no en una variable explicativa. Así, las transformaciones del espacio geográfico quedan en el ámbito de la geografía histórica, como si la geografía en su totalidad pudiese abstraer la temporalidad del ser. Aquí la abstracción no proviene de una visión empirista sino de una visión idealista que considera tiempo y espacio como formas del pensamiento que pueden ser separadas.

Retomando el pensamiento de Peter Hagget, Gregory (1996: 97), explica que "era la propia estructura que era geométrica" y agrega "el análisis locacional fue así organizado en torno de la descomposición de un sistema regional en una serie de geometrías abstractas: movimientos, redes, nódulos, jerarquías y superficies". Aun reconociendo el aporte de las rutinas tiempo-espacio expuestas en las geografías del tiempo de Hägerstrand, Gregory (1996) considera que la geografía tuvo un período en el cual dominó una ciencia espacial basada en un orden abstracto, geométrico, patronizado, incapaz de asimilar las inestables y emergentes configuraciones de la modernidad. Y rescata, como oposición a esas tradiciones, la idea de compresión tiempo-espacio de Harvey. Sin embargo, cuando propone incluir el individuo en el análisis geográfico a partir de las trayectorias, Hägerstrand (1970: 96) afirma que es necesario entender que una localización no se define solo por sus coordenadas espaciales sino también por coordenadas temporales. Y agrega: "podría ser bastante razonable eliminar el tiempo encubriéndolo con costes de transporte y de almacenamiento, en tanto que la manipulación de los materiales sea el principal interés del análisis locacional. Pero es poco razonable hacer esto cuando se presenta el problema de las personas. Por ejemplo, cuando en un modelo de equilibrio general, se asume que cada individuo juega una multitud de papeles, también está implícitamente admitido que la localización en el espacio no puede separarse del flujo del tiempo" (Hägerstrand, 1970: 96). Completa el geógrafo sueco: "el tiempo tiene una importancia vital cuando se trata de situar juntas a personas y cosas para el funcionamiento de los sistemas socioeconómicos, ya experimenten cambios a largo plazo o descansen en algo que podría definirse como un estado es- table" (Hägerstrand, 1970: 96). En otro trecho escribe: "el tiempo se mezcla con el espacio en una entidad espacio-temporal indivisible" (Hägerstrand, 1970: 99).

El primer enfoque aquí presentado no permitió sino incompletamente que la disciplina alcance un estatus científico y lo hizo fundamentalmente a partir de la formulación de principios de una geografía general, más lógicos que históricos, aplicados en una geografía regional, que aportaba las singularidades de sus contenidos empíricos. Al contrario, el segundo enfoque permitió a la geografía ocupar un lugar entre las ciencias pero al precio de abandonar su naturaleza histórica para asumir una naturaleza lógica y geométrica. No obstante, varios autores realizaron esfuerzos de integrar espacio y tiempo en investigaciones geográficas. J. M. Blaut (1961: 2) es uno de los geógrafos que critican la escisión espacio-tiempo y, para ello, recurre a la ironía de Whitehead sobre el siglo XIX al decir que era el siglo de la espacialización intelectual de las cosas, ya que la física trabajaba con el espacio absoluto de Newton y la filosofía con el aún más absoluto espacio de Kant. Para el geógrafo anglosajón el "espacio relativo está inseparablemente fusionado al tiempo relativo, ambos formando lo que es denominado espacio-tiempo (diverso/ múltiple), o simplemente proceso. Nada en el mundo físico es puramente espacial o temporal; todo es proceso. La dimensión tiempo puede ser ignorada, pero siempre está involucrada. Espacio puro no puede sobrevivir sino como una abstracción empírica [...] Espacio puro es de hecho relegado a las matemáticas puras, y cada concepto empírico de espacio debe ser reducible por una cadena de definiciones al concepto de proceso" (Blaut, 1961: 2). Isnard es otro geógrafo que buscó trabajar tiempo y espacio de forma integrada. En su opinión, "si admitimos que espacios geográficos y sociedades humanas se producen y se reproducen en interacciones dialécticas en el transcurso de su historia, es necesario que nuestra disciplina sitúe el objeto de sus investigaciones no solamente en el espacio, sino también en el tiempo" (Isnard, 1985: 534). En otro pasaje comenta: "con el desarrollo de los conocimientos y la eficacia de las técnicas sobre el control y la transformación de la naturaleza, el hombre sustituye al tiempo cósmico" por un tiempo histórico (Isnard, 1985: 542). Y explica que, tal vez más que 
otra disciplina, la geografía debe llevar en cuenta las discontinuidades en el espacio y en el tiempo (Isnard, 1985). Lamentando la visión cristalizada del espacio a lo largo de la historia de la geografía, Pierre George (1990: 124) explica que "una situación está hecha de estados y movimientos". Pero el problema ha sido que, al encontrar un nuevo orden de cosas, la geografía termina por analizarlo de manera estática, limitando la interpretación de situaciones conflictivas o de variaciones en el mercado de la producción o de los intercambios al simple reconocimiento de variables internas de la mecánica general. Por eso "la geografía no puede ser más el estudio de un estado de hecho" sino el estudio de los cambios (George, 1990: 159), pero agrega "la geografía se vuelve una crónica del tiempo presente, y el tiempo presente le escapa" (George, 1990: 159).

Aunque no puedan ser consideradas monolíticamente en virtud de la pluralidad de enfoques y métodos, las geografías críticas, radicales o marxistas y sus herederas han significado un aporte significativo en la reflexión sobre las relaciones espacio-tiempo. En estas vertientes ambas categorías, junto a otras categorías de la economía política, demandan un permanente ejercicio crítico de actualización para que sean capaces de explicar la novedad del período histórico. En ese contexto, el espacio es pensado en relación al modo de producción. Escribía Santos (1986: 138), en la década de 1970, que el espacio "testimonia un momento de un modo de producción por la memoria del espacio construido, de las cosas fijadas en el paisaje creado", pero aclaraba que el espacio "no es jamás un producto terminado, ni fijado, ni congelado para siempre" (Santos, 1986:150). Y, además, "la estructura espacial es, también, el pasado en el presente. Funciona según las leyes de lo actual, pero el pasado está presente. Además, el espacio aún en el presente es también futuro, por el hecho de la finalidad ya atribuida a las cosas construidas, al espacio producido" (Santos, 1986:151).

Es Anne Buttimer (1979: 244) quien afirmaba que "en nuestra generación surgió también el reconocimiento de la temporalidad y de la indivisibilidad del espacio-tiempo en el estudio de los géneros de vida contemporáneos", pues las nociones newtonianas de espacio y tiempo de dos dimensiones fueron sustituidas por la noción einsteniana del espacio-tiempo de cuatro dimensiones. Pero gran parte de las preocupaciones han permanecido en experiencias técnicas y racionales sin considerar la experiencia humana total. Entre los fenomenólogos, lamenta que las reflexiones sobre el espacio vivido y el tiempo vivido raramente hayan sido integradas (Buttimer, 1979: 250).

Para Jacques Lévy (1999: 157) lo que sabemos o creemos sobre el espacio y el tiempo se inscribe en un universo mental dominado por la naturalización y la sustancialización de esas dos nociones, pues "el naturalismo aplicado a la geografía y la reducción del espacio a la extensión no desaparecieron. El problema viene, no obstante, del privilegio acordado así al tiempo para medir el espacio. Hacer del tiempo la métrica fundamental en geografía participa de esta simetría indebida [...] No hay, en efecto, una razón general y permanente para darle un primado al tiempo en relación a otras dimensiones sociales en las cuales el espacio podría ser traducido: dinero, capital político, etc. A menos que, peor todavía, la ventaja del tiempo sea precisamente su inconveniente: el carácter euclidiano, así pues una utilización fácil, de su métrica convencional".

El período de la globalización, productor de nuevos objetos, nexos y metáforas, revirtió, de algún modo, esa subordinación del tiempo, que parece haber sido intrínseca a la tradición disciplinaria de la geografía, para postularlo a un lugar predominante, el de variable determinante capaz por sí de anular al espacio en el entendimiento del presente. Sin embargo, muchas veces ese tiempo tampoco ha sido visto en su empiricidad y ha dado lugar a una profusión de metáforas sobre el espacio, el territorio, la región y el lugar (Santos y Silveira, 1997).

\section{Por una dialéctica concreta: evento $y$ forma}

El problema de las relaciones entre tiempo y espacio ha sido, ciertamente, un leitmotiv en la historia de la disciplina. Sin embargo, una cuestión insoluble adviene del uso de una dialéctica que se vuelve abstracta 
exactamente por la abstracción de sus elementos: un tiempo cronológico y un espacio material, tantas veces reducido a la distancia, no alcanzan para empirizar ni uno ni otro en una existencia unitaria. Pero esa no ha sido la única dialéctica abstracta. Existe otra que parece haber adquirido más explicitación o visibilidad en el debate de la geografía y es la dialéctica sociedad-naturaleza, fiel a la lógica de los conceptos puros. Son también dialécticas incompletas en la medida en que tiempo y espacio no se niegan entre sí para generar un nuevo concepto, una nueva síntesis. Por eso las ideas de Heidegger (1975: 22) resultan reveladoras cuando, al preguntarse, “¿qué es una cosa?" afirma que es también una "pregunta espacio-temporal", que revela la "íntima unión de tiempo y espacio". Lo que parece estar en la base de esa disociación permanente de tiempo y espacio es la ausencia de la idea de evento. En su obra "The concept of nature", Whitehead (1994: 95) asevera que existe un evento donde quiera y cuando quiera que algo esté sucediendo. Agrega el autor (Whitehead, 1994: 93) que la continuidad de la naturaleza es la continuidad de los eventos. Para Ricœur (2000: 498): "es, en efecto, «dentro» del tiempo que los eventos ocurren" y añade "el 'ser-en-eltiempo' es el modo temporal de estar-en-elmundo" (Ricœur, 2000: 498), explicando que "estar-en significa entonces estar al lado - al lado de las cosas del mundo" (Ricœur (2000: 499).

Pero los eventos son unidades significativas del tiempo y, por esa razón, su duración no es regida por el reloj o el calendario sino por su significado social, su sentido y su capacidad de cambiar la trama de la historia. Transforman las posibilidades del período histórico en cualidades y cantidades o, en otras palabras, producen la extensión. "Los eventos son, simultáneamente, la matriz del tiempo y del espacio" (Santos, 1996: 115) y "cambian las cosas, transforman los objetos, dándoles, allí donde están, nuevas características" (Santos, 1996: 116). Como el evento es portador de un contenido nuevo y significativo, podríamos concordar con Chesneaux (1976: 132) cuando asevera: "el momento, a diferencia del evento puntual, es la cuestión de lo posible, es el momento donde todo deviene posible". Y se distancia de la historia événementiel al decir que la amplitud y el tamaño de esos momentos supera al evento, que es una expresión puntual, la punta del iceberg.

Los eventos son resultado de la acción y, por esa razón, no hay eventos sin actores. Pero sin formas, materiales e inmateriales, tampoco hay eventos, pues estas son su condición de existencia. O, como quiere Maffesoli (1997), la forma es formante y no formal. El evento se engarza en una forma disponible que es vacía sin su contenido y este no existe sin aquella. A cada evento la forma se reorganiza, cambia su contenido y su extensión. Cuando nos referimos a forma y evento es también de "forma-contenido" (Santos, 1986) que estamos hablando. Parafraseando a Simmel (2002), diríamos que, en cada fenómeno social, el contenido y la forma constituyen una realidad unitaria, aunque se vuelva muy difícil abandonar esa división entre forma y contenido, desprovista de cualquier obligación lógica o de la realidad percibida.

Vallaux (1929: 322) definía la geografía como una ciencia de formas y cosas concretas y explicaba que "en el mundo de las cosas concretas el espacio y el tiempo no están nunca separados". Pero fue también Carl Sauer (2000) quien encontró en la noción de forma una llave de interpretación de los espacios geográficos. Reflexionando sobre el cambio de las formas en el tiempo escribió: "formas actuales pueden ser derivadas de formas pasadas" (Sauer, 2000: 98). Podríamos entonces decir que las formas tienen un papel constitucional en la producción de la existencia. Por ello cuando Berger (1964) escribe que la interpretación correcta de los eventos del mundo supone el estudio de aquello que es su testimonio y que tal vez participa también de su producción, podríamos sustituir la palabra "testimonio" por la palabra "forma". En otros términos, sobre las formas materiales, culturales, organizacionales, normativas se realizan los eventos $y$, de ese modo, "las formas aseguran la continuidad del tiempo pero lo hacen a través de la sucesión de los eventos, que cambian su sentido" (Santos, 1996: 124). Arendt (2005:103) expresa esa dialéctica concreta: "el mundo de las cosas fabricado por el hombre se convierte en un hogar para los hombres mortales, cuya estabilidad perdurará y sobrevivirá al siempre cambiante movimiento de sus vidas y gestas solo en la medida en que trascienda la simple 
funcionalidad de los bienes de consumo y la utilidad de los objetos de uso".

De ese modo, el evento es un tiempo posible realizándose en un lugar real. Es el proceso socioespacial, que en su apariencia puede llevarnos a imaginar que hay un espacio y un tiempo, resultados provisorios de un proceso cambiante e infinito, tantas veces erigidos a categorías permanentes de interpretación del mundo. Como Heidegger, diríamos que si hay un espacio y un tiempo, en el origen del proceso no existían como tales, pues el ser solo puede ser aprehendido en la perspectiva del tiempo y el ser-ahí es, a la vez, temporal y espacial. Esa naturaleza provisoria podría ser mejor cualificada con las nociones de forma y evento, constitutivas de un proceso. Esta última noción parece revelar con más propiedad que espacio y tiempo no son categorías separadas. Sobre un espacio anterior se realizan los eventos presentes y lo que está tras el fenómeno percibido es un proceso, un acontecer. Categorías externas y filosóficas, forma y evento pueden ser internalizadas en geografía para dinamizar categorías internas, ya sean sintéticas como el espacio o analíticas como la división territorial del trabajo. Es un ejercicio de teorización o, en otras palabras, una actualización de categorías a la luz de la historia del presente.

\section{Empirización del tiempo, fenómeno técnico y periodización}

Si nos acercamos a una dialéctica más concreta a partir de las ideas de forma y evento, cabe ahora preguntarse cómo pensar esa dialéctica concreta en geografía o, más específicamente, cómo empirizar el tiempo y alcanzar una idea de período. Santos (1994: 42) propone: "empirizamos el tiempo tornándolo material, y de ese modo lo asimilamos al espacio, que no existe sin la materialidad. La técnica entra aquí como trazo de unión, históricamente y epistemológicamente". Y completa: "las técnicas, de un lado, nos dan la posibilidad de empirización del tiempo $y$, de otro lado, la posibilidad de una cualificación precisa de la materialidad sobre la cual las sociedades trabajan. Entonces, esa empirización puede ser la base de una siste- matización, solidaria con las características de cada época".

Atravesando las épocas las cosas pueden presentar la misma forma y llevarnos a una percepción engañosa sobre ellas mismas y sobre el tiempo. La continuidad de los eventos impide que las formas permanezcan iguales porque cambian su contenido. Por esas razones, la verdadera empirización del tiempo se alcanzará cuando, por medio de una periodización, podamos realzar el diferente valor de las formas-contenido, mostrando que es necesario "reducir" los isomorfismos para sorprender los eventos en su surgimiento originario y descubrir la novedad de la historia. De allí la pertinencia de una fenomenología.

En otras palabras, cada período histórico contiene un conjunto de posibilidades técnicas cuya realización, siempre selectiva, se revela en el espacio geográfico, un conjunto de formas y eventos. Podríamos decir que el espacio es continente y contenido de tales posibilidades pues, en cada momento, un modo de producir, de circular y de comunicar se vuelve posible. La técnica (forma) permite empirizar el tiempo porque su contenido (evento) es un contenido de tiempo, el tiempo de los objetos sobre el cual opera el tiempo de las acciones. En virtud de su realidad empírica, las técnicas permiten periodizar, porque son representativas de épocas históricas y revelan una forma de trabajar, de dividir y de distribuir el trabajo. Tiempo y espacio dejan de ser categorías a priori para tornarse conceptos históricamente datados.

A pesar de su recurrente sinonimia con la idea de tecnología, la noción de técnica aquí discutida busca ser más abarcativa $y$, de ese modo, vincularse con la idea de espacio geográfico. Ya en 1947 Mauss acuñó el vocablo "tecnomorfología" para señalar las relaciones recíprocas entre suelo y técnica y, más tarde, André Fel (1978) introdujo el neologismo "geotécnica". Citando a Marcuse, Habermas (1994) también define la técnica en un sentido amplio: dominación metódica, científica, calculada y calculante sobre la naturaleza y sobre el hombre. Proponiendo entender la técnica como el conjunto de objetos y formas de hacer, Santos (1996: 26) explica que "las técnicas son un conjunto de medios instrumentales y sociales, con los cuales el hombre 
realiza su vida, produce $y$, al mismo tiempo, crea espacio". Existe, por lo tanto, una indisolubilidad entre objetos y acciones, instrumentos y procedimientos, ya que las técnicas pueden ser vistas como "autorizaciones para hacer esto o aquello, de esta o de aquella forma, en este o en aquel ritmo, según esta u otra sucesión" (Santos, 1996: 45). La técnica, en su acepción de modo de hacer, es también reconocida por Gaudin (1978) cuando afirma que la llave del movimiento de las técnicas debe ser buscada en las modalidades de transmisión del saber-hacer. Esa naturaleza intrínseca de la materialidad y de la acción lleva a Ellul (1968: 101) a escribir que "la técnica es, por sí misma, un modo de actuar, exactamente un uso", pues no es posible utilizarla sin obedecer reglas técnicas. En otros términos, el objeto técnico (forma) impone un uso "amoldado" (evento), permite una acción limitada, pide una técnica de acción. En ese punto la indisolubilidad es absoluta ya que no recorrer ajustadamente los pasos indicados conduce al fracaso en la operación. No obstante, hay otro uso o acción, que admite cierta disociabilidad del objeto porque adviene de una combinación más amplia de factores sociales, políticos, económicos y culturales marcados por aceptaciones y rechazos (Silveira, 2010). Como señala Santos (1996), la acción política es el par histórico de la técnica. Por ello, el significado y el valor de la técnica no advienen de la técnica per se, sino del contexto en el cual se inserta.

Entretanto, no interesan tanto las técnicas particulares -técnicas industriales, agrícolas, políticas, electorales, presupuestarias- sino especialmente el fenómeno técnico. Ellul (1968: 2) ya podía escribir: "la técnica asume hoy en día la totalidad de las actividades del hombre, y no solo su actividad productora". Pero, si cada técnica particular es, en realidad, un método o un medio para alcanzar un resultado, la técnica en general puede ser entendida como un conjunto de medios, cuya naturaleza es hoy universal. Es el fenómeno técnico, tal como concebido por Ellul (1968).

La vida de las técnicas es sistémica (Santos, 1996). Cuando un sistema técnico alcanza su hegemonía durante un período, se vuelve la base material y organizacional de la sociedad pero, gradualmente, las innovaciones van a estructurar un nuevo sistema que lo sustituirá. Sin embargo, "no son los objetos que determinan los objetos" sino que "es el espacio que redefine los objetos técnicos, a pesar de sus vocaciones originales, al incluirlos en un conjunto coherente donde la contigüidad obliga a actuar en conjunto y solidariamente" (Santos, 1996: 34). No será suficiente considerar las cosas en sí, mas el espacio en su proceso de tornarse otro. Así, autores como Ellul (1968), Simondon (1989), Friedmann (1966) y Santos (1996) proponen considerar la técnica como un medio. Y, por consiguiente, cualquier porción del espacio en un determinado momento histórico es un palimpsesto de técnicas, de objetos y modos de trabajar, de formas y eventos.

La técnica puede ser vista, entonces, como medio y como fenómeno. Como un medio, es un conjunto de relaciones, un tejido de cosas y nexos tempoespaciales. Como fenómeno exige ir más allá de las apariencias, de lo visible, de lo tecnológico y entrar en lo invisible, en los nexos, en las relaciones. De allí que un período histórico no es un tiempo abstracto y cronológico sino un conjunto de existencias y posibilidades reales a disposición de los actores que viven ese momento. La idea de totalización de Sartre (1979) ayuda a entender que hay una totalidad haciéndose a través de los eventos -el período- que se transforma en una totalidad hecha, un conjunto de existencias, una facticidad, el espacio sorprendido en un momento. Esa facticidad tiene también un papel activo por su capacidad de abrigar o rechazar los eventos, condicionando el ejercicio de las acciones.

En tanto que recurso de método, la periodización significa elegir las variables clave que, en cada porción del tiempo, van a comandar el conjunto de formas y eventos. Se trata de un principio que permite valorizar los procesos y reconocer las novedades. Sin embargo, no cambian completamente los elementos viejos por los nuevos, hay permanencias y rupturas $y$, especialmente, coexistencias. Las variables no tienen comportamientos autónomos y, por eso, no parece aconsejable estudiar sus evoluciones particulares. La periodización también supone encontrar marcos significativos, eventos dentro de la continuidad, que resulten más relevantes para señalar las rupturas en las 
formas-contenido. En un período existen variables o grupos de variables que controlan el movimiento de reproducción de la totalidad. Cuando esa organización falla, por la evolución acelerada de una o más variables, adviene una crisis, una ruptura y un nuevo período. Con todo, lo más importante es caracterizar las épocas y menos los marcos que las separan. En palabras de Marx: "Se trata de encontrar los grandes rasgos, las características generales, pues en la historia de la sociedad ocurre como en la historia de la tierra, donde las épocas no se hallan separadas las unas de las otras por fronteras abstractas y rigurosas" (Marx, 1867: 302).

Aunque parece necesario comprender un período como una unidad, es también un desafío captar la heterogeneidad y verlo no un "flujo laminar" sino como un "flujo turbulento" (Latour, 1991:99). Por diferencias de poder económico y político, de localización, de cultura, de conciencia, en síntesis por las situaciones de existencia (Sartre, 1990), los actores no tienen igual fuerza en la aprehensión de las posibilidades. En cada momento histórico hay una redistribución del proceso social que no es ajena a las formas heredadas, delineando los usos del territorio.

\section{Globalización y geografía de la existencia}

De ese modo buscamos partir de las existencias concretas, entendidas como fenómenos y no como cosas en sí, e ir más allá para comprender sus relaciones sistémicas y sus nexos con lo que es posible en ese momento de la historia. Porque, como señaló Merleau-Ponty (2000), el espacio y el tiempo de las cosas son solamente harapos del tiempo. ¿Cuáles eran las posibilidades técnicas y políticas para los diversos actores en un determinado momento de la historia y en un lugar determinado? No partimos de un mundo de seres ideales sino de lo que existe, en un permanente ejercicio de actualización de las categorías para tornarlas conceptos.

La sociedad en movimiento solo se realiza en el espacio o, en otras palabras, el período produce un medio geográfico y el medio geográfico lo es de un determinado período. Por eso, no todas las posibilidades del período existen en todos los lugares y producen las mismas extensiones: no todas las técnicas llegan, en sus múltiples manifestaciones, a todos los lugares. Son los eventos que operan la metamorfosis entre posibilidad y existencia. Pero, frente a las existencias, la pregunta por las posibilidades es igualmente necesaria, pues asegura la verdadera crítica: la facticidad ha sido solo una combinación posible y no era ineluctable. Hubo otras posibilidades en el pasado, las hay en el presente y las habrá en el futuro. Como afirma Jaspers (1980: 93) "una realidad conocida es, en cuanto realidad, una posibilidad realizada".

Ladrière (1973), interpretando a Heidegger, explica que los seres con los cuales nos relacionamos son tomados en un juego de presencia y no presencia. Cuando se hacen presentes se nos vuelven accesibles. Pero el ser se da de una manera que no es total, se da velándose, disimulándose, ocultándose. $\mathrm{Y}$ agrega que como la presencia no es jamás total, hay diversas modalidades de presencia, es decir, diversas modalidades de desvelar y ninguna nos da el ser de manera absoluta. Ninguna existencia nos revela completamente el período o la temporalidad del ser. Aquí la idea de práctico-inerte de Sartre (1979) nos ayuda a comprender la dialéctica entre existencia y evento, entre facticidad y posibilidad y la necesidad de aprehender presencias y ausencias. El práctico-inerte es el reflejo puramente objetivo del hombre, esto es, la acción depositada en las cosas. Es la acción cristalizada en las formas materiales, jurídicas, culturales, morales. Es la actividad del hombre retornada porque "no hay materia que no condicione a la praxis humana a través de la unidad pasiva de significaciones prefabricadas [...] no hay hombre que no surja en el interior de un mundo de materialidades humanizadas, de instituciones materializadas y que no se vea prescribir un porvenir general en el seno del movimiento histórico" (Sartre, 1979: 304). La acción es capaz de transformar ese práctico-inerte, pero ninguna acción le es ajena porque forma parte de la situación en la que existimos y en la que los eventos se realizan. Es una circularidad dialéctica (Sartre, 1979), en la cual los hombres están mediados por las cosas y estas por los hombres. Las posibilidades del período no se realizan sin depararse con las existencias en 
los lugares, capaces también estos, a partir de sus actores, de generar eventos.

Esa circularidad dialéctica adquiere espesura hoy por la "ampliación de los contextos" (Santos, 1996), es decir, por la multiplicación de lugares y actores que participan de intercambios y conexiones, cada vez más acelerados y que generan nuevos comportamientos y percepciones. Diríamos, con Bagú (1986:104) que "el tiempo de nuestra realidad social nace con nuestra realidad social". De allí que la globalización es productora de un tiempo propio: un acontecer espeso e interrelacionado que se acompaña de la percepción de la simultaneidad y de la universalidad. A propósito de la discusión del tiempo real de Pierre Lévy, Dosse (2003: 375) escribe: "esa noción de tiempo real provoca una condensación en el presente" y este es "un tiempo íntimo social, interactivo, que sirve para coordinar los individuos, productores de entendimiento colectivo".

En cierto modo, novedad de nuestro período, la universalidad fue largamente preparada pues, como asevera Zerzan ( 2008:179), "el siglo XVII fue el primero en el que la gente se consideró a sí misma como habitantes de un determinado siglo", pero una sociedad más compleja "requiere un sistema mayor de señales temporales" (2008: 181). Ese embrión de sincronismo social debe mucho al reloj que, como sugiere Attali (1982:284), fue el primer sistema artificial capaz de producir cualquier cosa en serie, inclusive el propio tiempo, y agrega que "una transmisión instantánea del tiempo unifica el espacio y organiza un sincronismo planetario que desordena la organización de la mayor parte de los calendarios". El autor se refería al desorden producido en la dinámica del lugar; aquello que Hägerstrand (1970:101) interpretó de otra forma al decir que "el reloj y el calendario son los dispositivos antidesorden por excelencia". Ya Mumford (1982) se había referido a la "regimentación del tiempo" en el final del siglo XIX a partir de los ferrocarriles, agregada a la estandarización del tiempo de Greenwich.

No son pocos los autores que consideran que la historia universal, entendida como fusión de las historias particulares desarrolladas en diferentes rincones del planeta, ha comenzado en el siglo XVI. Esa parece ser la opinión de Chesneaux (1976) cuando describe los procesos de los últimos cinco siglos. Pero lo que nos interesa aquí es la idea de universalización de la historia: "no hay solamente ampliación geográfica de las corrientes de intercambios a través del planeta entero, y constitución de una historia universal en el sentido espacial del término. Simultáneamente, la historia de cada pueblo se transforma cualitativamente por la intervención de mecanismos unificadores y comunes" y, mencionando transformaciones de los mercados, explica que se universalizan "los mecanismos mismos de la historia" (Chesneaux, 1976: 104). Más allá de su limitada concepción de espacio, su explicación es fértil para ilustrar la complejidad del presente, pues la nueva dimensión del espacio revela una espesura, una profundidad del acontecer "gracias al número y diversidad enormes de los objetos, es decir, fijos, de que, hoy, es formado y al número exponencial de acciones, esto es, flujos, que lo atraviesan. Esa es una nueva dimensión del espacio, una verdadera quinta dimensión" (Santos, 1994: 38).

\section{Algunas palabras finales}

Gracias a una base material altamente tecnificada, constituida por técnicas de la información, en intrínseca asociación con las nuevas condiciones organizacionales y políticas, los eventos son interdependientes en su surgimiento originario y, así, asistimos a una verdadera historia universal. Hoy, algunos actores producen eventos técnicos y políticos que abarcan la totalidad del planeta y que, entrelazados, crean un conjunto de existencias planetarias. Es la primera vez en la historia que una generación recibe de otra objetos, acciones, relaciones e ideas universales, simultáneos e interdependientes, lo que puede ser denominado tiempo empírico (Santos, 1996).

Se trata de una profunda interrelación de los actores en el lugar, pues unos trabajan para otros compartiendo una base técnica, normativa e ideológica, aunque las relaciones sean desiguales y signadas por la subordinación y órdenes externas. Esta complejidad de formas-contenido puede ser enunciada como "unidad de lo múltiple" (Simmel, 2006:71). Cuando la técnica adquiere espesura, 
complejidad y escala parece aumentar la importancia epistemológica de abordar el fenómeno técnico, sus formas y contenidos temporales, sus nuevos nexos y, por lo tanto, su significado político pues, no parece aconsejable, trabajar la base técnica del presente como una cosa en sí.

De ese modo, el devenir puede ser pensado como un acontecer solidario, es decir, como la "realización compulsiva de tareas comunes, aunque el proyecto no sea común" (Santos, 1996: 132). Ese es el cerne de la globalización que muchos asocian a la idea de un tiempo único, de una división territorial del trabajo ineluctable, de un conjunto inexorable de existencias materiales e inmateriales modernas. El acontecer solidario es un tiempo universal que se hace empírico, pero no suprime temporalidades $\mathrm{o}$, en otras palabras, no elimina los tiempos dentro del tiempo, la relatividad del tiempo, las posibilidades diferentes de interpretación y uso de las variables contemporáneas. Emerge la conciencia de ese tiempo universal que dicta la compulsión de las tareas comunes, pero muy lejos está de desvanecer las temporalidades, de igualar las velocidades y de imponer un proyecto común. Como un período es un movimiento de impactos selectivos, los eventos revelan manifestaciones diversas. Para Santos (1994: 46) "Io que Ilamamos tiempo universal es ese tiempo que abarca los otros tiempos, que valoriza diferentemente el espacio banal, según la fuerza de los agentes de la economía, de la sociedad, de la política, de la cultura".

En otras palabras, cuando las posibilidades se encuentran con lo que ya existe, con el práctico-inerte, se tornan nuevas existencias, se esencian, diría Heidegger (2003), cambian las formas-contenido, se crean nuevas extensiones y nuevas especializaciones territoriales. Sin embargo, el mundo no es solo el orden resultante de una división del trabajo unívoca, de especializaciones productivas modernas, sino particularmente un espacio banal, es decir, un conjunto heterogéneo de existencias, que recibe diferencialmente los eventos y que es utilizado por todos los actores. Por ello el espacio banal es el espacio de todos, un proceso con diversas formas y eventos, un contenido de tiempo que, por eso, no puede ser analizado a partir de categorías geométricas o congeladas.
Parece necesario ir más allá de la cosa en sí y captar la vida en las formas, a partir de una teorización, es decir, del encuentro de las categorías más apropiadas a la historia de cada momento, a las existencias y procesos de cada presente, para buscar una geografía de la existencia. Hoy podríamos decir que el tiempo dejó de ser abstracto y se hizo empírico porque está mediado por objetos y normas, que pasan de una generación a otra, revelando la solidaridad o interdependencia originaria como trazo principal de su historicidad. El tiempo adquiere materialidad en esa interdependencia y, así, se vuelve una categoría histórica y concreta de pensamiento. La globalización, demandante de conceptos híbridos, desvanece la dicotomía entre el tiempo como categoría de pensamiento o como realidad material. Hoy, más que nunca, los estudios geográficos podrán ofrecer una interpretación crítica del mundo si aceptan el desafío de aprehender la temporalidad del espacio y la empiricidad del tiempo, que podrán ser analizadas a partir del fenómeno técnico en cada momento de la historia y en la diversidad de sus manifestaciones.

\section{Referencias bibliográficas}

ARENDT, H. De la historia a la acción. Buenos Aires: Paidós, 2005.

ATTALI, J. Histoires du temps. Paris: Fayard, 1982.

BACHELARD, G. La dialectique de la durée. Paris: PUF, 1950.

BAGU, S. Tiempo, realidad social y conocimiento. México: Siglo XXI, 1986.

BERGER, G. Phénoménologie du Temps et Prospective. Paris: PUF, 1964.

BERGSON, H. Durée et simultanéité. Paris: PUF, 1923.

BERRY, B. Un paradigma para la Geografía moderna. En: CHORLEY, R. J. (editor). Nuevas tendencias en Geografía. Madrid: Instituto de Estudios de Administración Local, 1975, p. 11-38.

BLAUT, J.M. Space and process. The Professional Geographer, 1961, Vol. XIII, № 4, p. 1-7. 
BLOCH, M. Introducción a la historia. México: FCE, 1975.

BORZAGA, R. Contemporary Philosophy. Phenomenological and Existential Currents. MiIwaukee: The Bruce Publishing Company, 1966.

BRAUDEL, F. La historia y las ciencias sociales. Madrid: Alianza, 1989.

BRUNHES, J. La Géographie Humaine. Paris: PUF, 1947.

BRUNHES, J. El carácter propio y el carácter complejo de los hechos de Geografía Humana. En: GÓMEZ MENDOZA, J.; MUÑOZ JIMÉNEZ, J. y ORTEGA CANTERO, N. El pensamiento geográfico. Estudio interpretativo y antología de textos (De Humboldt a las tendencias radicales). Madrid: Alianza, 1988, p. 252-266.

BUNGE, W. Geografía Teórica. Una metodología geográfica. En: GÓMEZ MENDOZA, J.; MUÑOZ JIMÉNEZ, J. y ORTEGA CANTERO, N. El pensamiento geográfico. Estudio interpretativo y antología de textos (De Humboldt a las tendencias radicales). Madrid: Alianza, 1988, p.402-411.

BURTON, I. La revolución cuantitativa y la Geografía teórica. En: GÓMEZ MENDOZA, J.; MUÑOZ JIMÉNEZ, J. y ORTEGA CANTERO, N. El pensamiento geográfico. Estudio interpretativo y antología de textos (De Humboldt a las tendencias radicales). Madrid: Alianza, 1988, p. 412-420.

BUTTIMER, A. Le temps, I'espace et le monde vécu. L'Espace Géographique, 1979, $N^{\circ} 4$, p. 243-254.

CASSIRER, E. Filosofía de la llustración. Madrid: FCE, 1993.

CHESNAUX, J. Du passé faisons table rase? A propos de l'histoire et des historiens. Paris: Maspero, 1976.

DASEY, M. F. Algunas cuestiones en torno a las distribuciones espaciales. En: CHORLEY, R. J. (editor). Nuevas tendencias en Geografía. Madrid: Instituto de Estudios de Administración Local, 1975, p. 189-221.
DEMANGEON, A. Problèmes de Géographie Humaine. Paris: Armand Colin, 1952.

DOSSE, F. O império do sentido: a humanização das ciências humanas. Bauru: Edusc, 2003.

DURKHEIM, É. Las reglas del método sociológico. Barcelona: Orbis, Colección Historia del Pensamiento, 1985.

ELLUL, J. A técnica e o desafio do século. Rio de Janeiro: Paz e Terra, 1968.

FEBVRE, L. La Terre et l'évolution humaine. Introduction géographique à l'histoire. Paris: Albin Michel, 1970.

FEL, A. La géographie et les techniques. En: Histoire des Techniques. Paris: Encyclopédie de la Pléiade, 1978, p. 1062-1110.

FRIEDMANN, G. Sept Études sur l'homme et la technique. Paris: Denoel/Gonthier, 1966.

GAUDIN, Th. L'écoute des silences, les institutions contre l'innovation? Paris: Union Générale des Éditions, 1978.

GEORGE, P. Le métier de géographe. Un demi-siècle de Géographie. Paris: Armand Colin, 1990.

GOURU, P. Por une Géographie Humaine. Paris: Flammarion, 1973.

GREGORY, D. Teoria social e geografia humana. En: GREGORY, D.; MARTIM, R.; SMITH, G. (editores). Geografia Humana. Sociedade, Espaço e Ciência Social. Rio de Janeiro: Jorge Zahar, 1996, p. 90-122.

HABERMAS, J. Técnica e Ciência como "Ideologia". Lisboa: Edições 70, 1994.

HÄGERSTRAND, T. ¿Qué hay acerca de las personas en la ciencia regional? Traducción de "What about people in Regional Science?". Papers of the Regional Science Association, 1970, Vol. 24, p. 7-21.

HARTSHORNE, R. Propósitos e natureza da Geografia. São Paulo: Hucitec-Edusp, 1978. 
HARVEY, D. Explanation in Geography. Some general problems. Londres: Edward Arnold, 1969.

HEIDEGGER, M. La pregunta por la cosa. La doctrina kantiana de los principios trascendentales. Barcelona: Orbis, Colección Historia del Pensamiento, 1975.

HEIDEGGER, M. Aportes a la filosofía. Acerca del evento. Buenos Aires: Biblioteca Internacional Heidegger, Biblos, 2003.

HEIDEGGER, M. Ser e Tempo/Sein und Zeit. Campinas-Rio de Janeiro: Unicamp-Vozes, 2012.

HETTNER, A. La naturaleza de la Geografía y sus métodos. En: GÓMEZ MENDOZA, J.; MUÑOZ JIMÉNEZ, J. y ORTEGA CANTERO, N. El pensamiento geográfico. Estudio interpretativo y antología de textos (De Humboldt a las tendencias radicales). Madrid: Alianza, 1988, p. 311-322.

HOTTOIS, G. Historia de la Filosofía del Renacimiento a la Posmodernidad. Madrid: Cátedra, 1999.

HUSSERL, E. A ideia da fenomenologia. Lisboa: Edições 70, 1990.

ISNARD, H. Espace et Temps en Géographie. Annales de Géographie, 1985, N 525, p. 534-545.

JASPERS, K. Filosofía de la existencia. Buenos Aires: Aguilar, 1980.

KANT, I. Crítica de la razón pura. Barcelona: Orbis, Colección Historia del Pensamiento, 1984 .

LACOSTE, Y. La Géographie et I'Histoire. L'Information Géographique, 1984, № 48, p. 71-74.

LADRIÈRE, J. Vie sociale et destinée. Gembloux: Duculot, 1973.

LATOUR, B. Nous n'avons jamais été modernes. Essai d'anthropologie symétrique. Paris: La Découverte, 1991.
LEIBNIZ, G. Monadología. Discurso de Metafísica. La profesión de fe del filósofo. Barcelona: Orbis, Colección Historia del Pensamiento, 1983.

LÉVY, J. Le tournant géographique. Penser l'espace pour lire le monde. Paris: Belin, 1999.

MAFESSOLI, M. Elogio de la razón sensible. Una visión intuitiva del mundo contemporáneo. Buenos Aires: Paidós, 1997.

MARX, K. El Capital. Crítica de la Economía Política. Tomo I. México: FCE, 1986.

MERLEAU-PONTY, M. O visível e o invisível. São Paulo: Perspectiva, 2000.

MUMFORD, L. A cidade na história. São Paulo: Martins Fontes, 1982.

PARMÉNIDES. Sobre la naturaleza. En: Parménides - Zenon - Meliso (Escuela de Elea), Fragmentos. Barcelona: Orbis, Colección Historia del Pensamiento, 1983.

PIETTRE, B. Filosofia e Ciência do tempo. Bauru: Edusc, 1997.

RAZTEL, F. El territorio, la sociedad y el Estado. En: GÓMEZ MENDOZA, J.; MUÑOZ JIMÉNEZ, J. y ORTEGA CANTERO, N. EI pensamiento geográfico. Estudio interpretativo y antología de textos (De Humboldt a las tendencias radicales). Madrid: Alianza, 1988, p.193-203.

RICCEUR, P. La mémoire, l'histoire, l'oubli. Paris: Éditions du Seuil, 2000.

RUSSELL, B. El conocimiento humano. Barcelona: Orbis, Colección Historia del Pensamiento, 1983.

SANTOS, M. Por uma Geografia nova. Da crítica da Geografia a uma Geografia Crítica. São Paulo: Hucitec, 1986.

SANTOS, M. Técnica, Espaço, Tempo. Globalização e Meio Técnico-Científico-Informacional. São Paulo: Hucitec, 1994.

SANTOS, M. A natureza do espaço. Técnica e Tempo. Razão e Emoção. São Paulo: Hucitec, 1996. 
SANTOS, M. y SILVEIRA, M. L. De uma geografia metafórica da pós-modernidade a uma geografia da globalização. Cultura Vozes, 1997, Vol. 91, No 4, p. 14-30.

SARTRE, J.-P. Crítica de la Razón Dialéctica. (Precedida de Cuestiones de Método). Buenos Aires: Losada, 1979.

SARTRE, J.-P. Situations Philosophiques. Paris: Gallimard, 1990.

SAUER, C. Desenvolvimentos recentes em Geografia Cultural. En: CORRÊA, R. L. y ROSENDAHL, Z. (editores). Geografia Cultural: um século (I). Rio de Janeiro: Eduerj, 2000, p. 15-98.

SILVEIRA, M. L. Espaço geográfico e fenômeno técnico: por um debate substantivo. En: BOMFIM, P.R.A. y SOUSA NETO, M.F. (editores). Geografia e Pensamento Geográfico no Brasil. São Paulo: Annablume, 2010, p. 123-139.

SIMMEL, G. Sobre la individualidad y las formas sociales. Bernal: Universidad Nacional de Quilmes, 2002.

SIMMEL, G. Problemas fundamentales de la Filosofía. Andalucía: Espuela del Plata, 2006.
SIMONDON, G. Du mode d'existence des objets techniques. Paris: Aubier, 1989.

SORRE, M. Les fondements de la Géographie Humaine. Tome II (Les fondements techniques). Paris: Armand Colin, 1948.

STAMP, L. D. Geografía aplicada. Buenos Aires: Eudeba, 1981.

VALLAUX, C. Les sciences geógraphiques. Paris: Félix Alcan, 1929.

VIDAL DE LA BLACHE, P. Princípios de Geografia Humana. Lisboa: Cosmos, 1946.

WHITEHEAD, A.N. O conceito de natureza. São Paulo: Martins Fontes, 1994.

ZERZAN, J. "Hora de rezar, hora de trabajar". Extraido de Future primitive and other essays. En: INDIJ, G. (editor). Sobre el tiempo. Buenos Aires: La marca, 2008, p. 178-182.

ZUSMAN, P. Geografías históricas y fronteras. En: LINDÓN, A. y HIERNAUX, D. (editores). Tratado de Geografía Humana. Barcelona-México: Anthropos-División Ciencias Sociales y Humanidades, p. 170-186. 